\title{
Discussing Resuscitation Preferences with Patients: Challenges and Rewards
}

Eva H. Chittenden, MD ${ }^{1}$

Susannah T. Clark, $\mathrm{MD}^{2}$

Steven Z. Pantilat, $\mathrm{MD}^{1}$

${ }^{1}$ Department of Medicine, University of California, San Francisco, San Francisco, California

${ }^{2}$ Department of Medicine, Dartmouth Medical School, Hanover, New Hampshire
This paper was submitted on behalf of the Palliative Care Task Force.
Discussing preferences regarding resuscitation is a challenging and important task for any physician. Understanding patients' wishes at the end of life allows physicians to provide the type of care patients want, to avoid unwanted interventions, and to promote patient autonomy and dignity. Hospitalists face an even greater challenge because they are often meeting a patient for the first time in a crisis situation. Despite the frequency with which clinicians have these conversations, they typically fall short when discussing code status with patients. In this evidencebased review, we discuss physician barriers to conducting effective discussions, offer a variety of approaches to enhancing these conversations, and review important communication techniques. Journal of Hospital Medicine 2006;1:231-240. (C) 2006 Society of Hospital Medicine.

KEYWORDS: resuscitation discussions, hospitalists, patient autonomy, communication techniques, advanced serious illness.

Mrs. $\mathrm{G}$ is a 58-year-old woman with metastatic pancreatic cancer, diagnosed 8 months prior to admission when she presented to her primary care doctor with abdominal pain and weight loss. The cancer was locally advanced and metastatic to the liver at the time of diagnosis, and she underwent first-line palliative chemotherapy with gemcitabine without objective or symptomatic improvement. She is now admitted to the hospitalist service with intractable abdominal pain, uncontrolled on her outpatient doses of opioids. On the day after admission, her pain is well controlled on morphine via patient-controlled anesthesia. The hospitalist decides to talk with her about her about resuscitation status. At this point, she is full code.

Dr. S sits down with her and says, "There's something I need to talk with you about that I talk with all of my patients about. And that is, if your heart were to stop, and mind you, I'm not expecting this to happen anytime soon, do you want us to do everything possible to bring you back?"

Dr. S pauses to catch his breath, and then Mrs. G says, "Well, I guess so, if you thought you could bring me back."

He continues, "We are not always successful at bringing people back, but let me explain what this would entail: we could do chest compressions, administer shocks to your heart, put a breathing tube down into the back of your throat, hook you up to a machine that helps you breathe..."

Mrs. G glances up with a confused look. Dr. S says, "You know, Mrs. G, I've started this conversation all wrong. I'm going to step out for a few minutes, collect my thoughts, and come back to talk with you again. Is that OK?" Mrs. G smiles and says, "Of course."

The doctor reenters the room about 20 minutes later, pulls up a chair next to her bed, and in a relaxed tone of voice says, "Tell me what you understand about your illness."

Mrs. G says, "I understand that I have cancer in my pancreas and liver and that I may not last very long, perhaps months if that. My oncologist offered me more chemotherapy, but I decided against it because it didn't 
seem that it would offer me much. And the first chemotherapy was really hard." most?"

Dr. S then asks, "As you look ahead, what worries you

Mrs. G replies, "I really worry that I will die in terrible pain. That scares me terribly. I also worry about my husband and how he's going to cope with my worsening condition and with my death, let alone my pain."

Dr. S then says, "That sounds really frightening. Tell me more about that." She continues, "Well, I really want to spend the time I have left with my husband and family - my children and grandchildren-and I want to have some good time with them. But I keep worrying that it won't be able to be that way." She starts crying. "You know, I'm so scared about going home and being in terrible pain again and having my husband and family be terrified..."

She pauses for a moment. The doctor doesn't say anything.

She starts up again, “But I don't want to end up in the hospital again.... I don't want to end up on machines like my mother-in-law did...." She looks up at Dr. S, expecting a response.

Dr. S takes her hand and says, "You know, I realize this is not easy to talk about, but it's really important for me to hear about your worries so that I can know how to help. The good news is we have many good methods to control your pain and that we can help you to be comfortable and to remain at home...."

"Thank you. Thank you so much."

A $s$ these conversations illustrate, discussing preferences regarding resuscitation is a challenging and important task for physicians. Understanding patients' wishes at the end of life allows clinicians to provide the type of care patients want, to avoid unwanted interventions, and to promote patient autonomy and dignity. Despite the frequency with which physicians have these conversations, they typically fall short when discussing code status with patients. Clinicians fail to address patients' concerns, monopolize conversations, and commonly misunderstand patients' resuscitation preferences. $^{1-3}$ Often these discussions do not occur at all; more than $70 \%$ of seriously ill patients have never discussed advance directives with their physician. $^{2,4}$ The multicenter SUPPORT study, which demonstrated serious problems in the care of seriously ill hospitalized patients, documented that only $47 \%$ of physicians knew when their patients preferred do-not-resuscitate status. ${ }^{5}$

Hospitalists frequently conduct resuscitation discussions. Patients who are admitted to the hos- pital are usually seriously ill, and hospitalists need to assess rapidly whether an individual patient would want a resuscitation attempt if he or she had a cardiopulmonary arrest in the hospital. They need to build trust and rapport quickly with patients they have never met. Despite this challenge, hospitalists are in a good position to discuss resuscitation preferences. ${ }^{6}$ Patients may be more willing to discuss these issues in inpatient rather than outpatient settings because their acute deterioration may encourage self-reflection. ${ }^{6}$ Furthermore, the time and productivity pressures of office practice often make it difficult for primary care physicians, who often know the patient and family best, to address advance directives. Although studies have documented that patients are interested in talking to their primary physicians about these matters, ${ }^{7,8}$ these conversations do not occur with regularity. Preliminary research has raised the possibility that cancer patients may actually prefer to discuss these issues in an inpatient setting with a hospital-based provider rather than with their oncologists. ${ }^{9}$ Studies have not addressed the question of whether patients with diseases other than cancer would prefer to discuss these issues with a hospitalist or their outpatient subspecialist.

Given that more than half of all Americans die in hospitals, hospitalists care for many people who are terminally ill and will need to assess preferences for cardiopulmonary resuscitation (CPR) and other treatments. Hospitalists need to be competent and compassionate in their approach to patients and their families. In this articles we review clinician barriers to holding these conversations, offer a variety of approaches to enhance these discussions, and review communication techniques that can be used to improve understanding.

\section{Clinician Barriers to Discussing Resuscitation}

Clinicians' own barriers may lead to infrequent and inadequate conversations about resuscitation. Understanding these barriers may allow providers to overcome them and facilitate better and more frequent communication. A discussion of patient barriers is beyond the scope of this article.

\section{Unresolved Feelings about Death and Dying}

When discussing resuscitation, or code status, physicians are discussing the possibility of death with a patient. In the first scenario above, the clinician lists the many procedures that could be done if the patient's "heart were to stop" without using the 
words die or death. The clinician never explicitly acknowledges that the patient has a serious illness that could lead to her death. Medical culture is focused on cure and on warding off death until the last possible moment. Because clinicians work in this culture, many have unresolved feelings of personal failure that are triggered when treating a dying patient. ${ }^{10}$ Also, the death of a patient can lead to anxieties about the clinician's own mortality and raise uncomfortable feelings of loss, related to the patient or to memories of deaths of the clinician's loved ones. In an attempt to avoid these feelings, whether conscious or not, physicians may resist talking to patients about death. ${ }^{10}$

\section{Fear of Taking Away Hope}

Clinicians fear that patients will lose hope if they are too honest about prognosis and acknowledge the inevitability of death. This concern may be true for a small minority of patients with advanced terminal illness who are solely focused on continued treatment and in such denial that they never consider the possibility of death. Most patients, however, understand on some level that they are getting sicker and may die, but expect clinicians to initiate discussions about death and dying. ${ }^{8,11}$ Clinicians should understand that patients can have hope about many things beyond cure of their illness. For example, they can hope for good control of their symptoms so they can spend meaningful time with family and friends, heal troubled relationships, create a legacy, and say good-bye. As in other developmental stages throughout life, the process of dying can be a time of emotional and spiritual growth and provide an opportunity to deepen relationships and find greater meaning. ${ }^{12}$ Despite their fears, physicians are much less likely to take away hope than they think. In fact, they can carry out the important actions of helping patients to refocus on more attainable goals and helping to return hope to what may be perceived by all as a hopeless situation. $^{13,14}$

\section{Inadequate Training}

There have been many educational interventions in both outpatient and inpatient settings to encourage physicians to discuss advance directives with patients. ${ }^{15-21}$ In most of these studies, clinicians were sent reminders, but did not receive training or feedback to improve their communication skills. Although these interventions have led to modest increases in the number of advance directives, little is known about the quality of the conversations between clinician and patient.

There are acknowledged deficits in undergraduate $^{22}$ and graduate medical education in discussing preferences and goals of care with patients. ${ }^{23,24}$ A national survey of medical education deans showed that two-thirds believed insufficient time was given to palliative care education including communication skills. ${ }^{25}$ Reflecting this lack of training, medical students and residents feel unprepared to take care of dying patients. ${ }^{26}$ In one survey, hospitalists reported that although palliative care was very important to their practice, they had not received enough training in palliative care knowledge and skills. ${ }^{27}$

\section{Traditional Ethical Frameworks}

Another difficulty arises from myths about the ethical perspectives that inform medical decision making and obtaining informed consent. Although these perspectives highlight the importance of patient autonomy and the right of the individual to choose medical treatments, they do not require physicians to describe every possible treatment if, in the clinician's judgment, a particular treatment would not benefit a patient. Physicians do have an obligation to use their medical knowledge and judgment in offering treatments and discussing side effects. ${ }^{28}$ In an attempt to honor a patient's autonomy when discussing advance directivesand possibly out of fear of coercing patients-clinicians sometimes offer a menu of treatment options without exploring the patient's underlying goals for these treatments. This approach can become meaningless out of context if the patient does not understand the probability that these interventions will work or the interrelatedness of the interventions. For example, when given a list of choices regarding resuscitation, a patient may say, "I would like chest compressions and a chest tube, but no shocks please." Such a statement makes little sense clinically. Instead, physicians should have meaningful conversations with their patients in which they describe treatment options in the context of patient goals and values and help patients come to decisions in a shared process.

\section{Practical Concerns}

Outpatient providers find that time constraints and the competing demands that occur in caring for patients with multiple chronic health problems make it difficult to discuss advance directives. ${ }^{29}$ 
Hospitalists are also subject to productivity pressures and may feel similarly stressed for time. Outpatient providers spend about 5 minutes on each of these conversations, ${ }^{1}$ and medicine residents in the inpatient setting spend about 10 minutes. ${ }^{30}$ However, many of the conversations studied were inadequate; thus, it is unknown how long it takes to have an effective conversation. Hospitalists should keep in mind that they need not have these discussions every day with each patient and that having these conversations may end up saving time in the long run if they have a clearer sense of a patient's wishes and goals.

\section{Laying Groundwork for the Discussion}

The decision regarding resuscitation should be seen in the context of the patient's goals and values and overall health status. To address code status effectively, it is imperative first to elicit the person's view of his/her illness and then gently correct any misunderstandings. A patient who thinks her/his life will go on indefinitely may feel no need to consider her/his own mortality or alternatives to full resuscitation status. Alternatively, a patient who senses his/her mortality may have already thought about resuscitation and have clear preferences. A key first step in the conversation is to understand a patient's values and goals and comprehension of his/her illness. As in the second discussion above, a clinician can begin a discussion by saying, "Tell me what you understand about your illness."

Discussing prognosis with patients can be difficult as physicians struggle with uncertainty. In the most comprehensive study to date of prognostication, physicians overestimated patient survival on average by a factor of $5 .{ }^{31}$ Nonetheless, there are compelling reasons to discuss prognosis. Failure to do so often results in patients spending their last days in the hospital receiving more aggressive treatments than they might choose if they understood their prognoses. ${ }^{32}$ Further, patients are denied the opportunity to address issues of life closure, such as spending time with family, thinking about legacy, and settling financial affairs. Physicians also fear they will take away hope with prognostication and believe patients expect greater accuracy than they can provide. ${ }^{33}$

Physicians can improve their prognostication skills by considering patients' functional status and clinical signs and symptoms and by using validated scales. The Karnofsky Performance Score (KPS) and the Eastern Cooperative Oncology Group (ECOG)
TABLE 1

Introducing the Subject of Resuscitation

- "When I take care of patients with advanced cancer [or heart disease or lung disease, etc.], I like to talk with them about their wishes for care if they were to get very sick and even die suddenly. Is that all right?"

- "As you look ahead, what worries you most?"

- "As you look to the future, what do you hope for?"

- "Has a close friend or family member ever been really sick?"

- "If you were to get so sick that you were unable to make decisions for yourself, who would you want to make them for you?"

- "Is there any state that would be worse than death for you?"

Performance Status have been shown to correlate with survival, ${ }^{34-40}$ and the Palliative Prognostic Score $(\mathrm{PaP})$ has been validated in both cancer and noncancer patients. ${ }^{41,44-46}$ The PaP uses a combination of the KPS, clinical signs and symptoms, and the clinician's clinical prediction of survival. In addition, clinicians can be honest with patients about prognostic uncertainties and give prognoses in ranges, such as "days to weeks," or "weeks to months."

\section{How to Broach the Subject of Resuscitation}

In the first scenario presented in this article, the hospitalist says, "There's something I need to talk with you about that I talk with all of my patients about." Although many clinicians begin resuscitation discussions this way, the question is problematic because often it is untrue. Most clinicians do not discuss code status with all patients who are admitted to the hospital. A better option would be to say, "When I take care of patients with advanced cancer, I like to talk with them about their wishes regarding resuscitation. Is that all right?" Better yet would be to ask a general question such as "As you look ahead, what worries you most?" or "As you look to the future, what do you hope for?" These and other useful questions appear in Table 1. These questions allow patients to bring up their concerns, show that the clinician cares about them, and often segue into a discussion of patients' hopes and worries about their own death and dying process. These questions often allow patients to bring up important goals that bear directly on the issue of resuscitation. For example, in the second scenario at the beginning of the article, the patient says she wants to have quality time with her family at home and does not want life-sustaining technologies. Such a patient may not want resuscitation. When discussing CPR, it can also be helpful to state ex- 
plicitly that resuscitation is used when a patient has died, rather than to use euphemisms such as, "If your heart were to stop...." The clinician can ask explicitly, "If you were to die, would you want...?" There are other strategies for introducing the subject of resuscitation if these questions do not work. If a patient seems uncomfortable with the conversation, the clinician can address this discomfort directly by saying, "This conversation seems to make you uncomfortable." Other strategies for exploring these issues include inquiring if the person has ever discussed resuscitation with his/her family or another physician, or asking if anyone else in the family has been very sick. Additionally, clinicians can ask questions about surrogate decision making. "If you were to get so sick that you were unable to make decisions for yourself, who would you want to make them for you?" This can then lead into a discussion of whether the patient has spoken to that person about his/her preferences, and if so, what was the content of that conversation. Another useful question is, "Is there any state that would be worse than death for you?" This question focuses on outcomes and allows the physician to put the issue of resuscitation into perspective for a patient.

\section{Knowing the Facts about Cardiopulmonary Resuscitation}

In general, about 1 in 7 patients who have undergone CPR in the hospital survive to hospital discharge. Two literature reviews, from 1989 and 1998, of hospitalized patients who underwent CPR in the hospital reported surprisingly similar statistics. Immediate survival in both series was $41 \%$, and survival to hospital discharge was $13 \%-14 \%$. Factors that increased survival included arrest due to coronary artery disease or drug overdose/adverse reaction, and location of arrest in the intensive care unit (ICU). Factors that decreased survival included sepsis at time of arrest, cancer, whether localized or metastatic, dementia, acute renal failure, bedbound status, and residence in a nursing home. Neither age nor sex was associated with survival. ${ }^{47,48}$ In a meta-analysis of outcome studies of CPR in metastatic cancer patients, none of 117 patients survived to hospital discharge. ${ }^{49}$

Most people get their information about CPR survival rates from the mass media, which portray $\mathrm{CPR}$ as a very successful procedure. For instance, on television, the sole source of information on CPR for most patients, the rate of survival to hospital discharge is $64 \%$, much higher than the $13-14 \%$ cited in the medical literature. ${ }^{50}$ Thus, it is no sur- prise that a patient with metastatic cancer or another life-limiting illness would assume a positive outcome with CPR.

Knowledge of the facts about CPR survival rates is key when a physician discusses code status with a patient because these data influence patients' decisions. Patients who have a realistic understanding of their chances are less likely to prefer resuscitation. ${ }^{51,52}$ Offering patients information about the success rate for CPR in their particular situation is critical in helping them reach a decision consistent with their values and goals. This information can be given quantitatively or qualitatively depending on the clinician assessment of what the patient would prefer.

\section{Avoiding Stark Dichotomies in Resuscitation Discussions} In clinical practice there are 3 ways in which physicians can present resuscitation decisions as black and white and ignore the shades of gray. First, clinicians may present the choice between resuscitation and do not resuscitate (DNR) as a choice between life and death. In the first scenario above, the physician states "If your heart were to stop, do you want us to do everything to bring you back?" implying he would be able to save the patient's life with resuscitation attempts. When discussing resuscitation, clinicians should avoid language that suggests such a stark dichotomy. The reality is that most patients die despite resuscitation attempts. In fact, a patient is actually choosing between certain death (without resuscitation) and likely death (if resuscitation is attempted). For a patient with a serious, life-limiting illness, it may be more effective to frame the conversation in terms of how that person envisions the end of life, and not whether death will eventually occur.

Second, clinicians and patients sometimes equate DNR with doing nothing or giving up. Clinicians fail to discuss other treatment options or alternatives, such as continuing ongoing aggressive medical treatments with DNR status or pursuing palliative care. Performing resuscitation is equated with activity and treatment, whereas withholding resuscitation is seen as passivity and giving up. To the patient, this can feel like abandonment, as if the doctor is withholding a treatment and not offering anything in its place. Examples of positive phrases that demonstrate the physician will continue to offer excellent care include: "We will continue maximal medical therapy. However, if you die despite these treatments, we will let you die peacefully and 
won't attempt to revive you"; "We'll continue the intravenous antibiotics, but we won't plan to move you to the ICU if things worsen"53; and "We will work hard to treat your pain and other symptoms and to get you home." In addition, hospitalists must ensure, when signing out to physician colleagues, nurses, respiratory therapists, and others, that DNR orders are not overinterpreted to mean "no treatment." Although a DNR order states that in the event of a cardiac arrest, no attempt at resuscitation will be made, it should have no bearing on other appropriate and desired interventions, including antibiotics, chemotherapy, and artificial nutrition; treatment for pain and other symptoms; and even monitoring in an ICU. This misunderstanding of DNR status is common among health care providers and has led many to argue that DNR orders should be part of a more comprehensive treatment plan that outlines where the patient's wishes for treatment fall on the spectrum from "otherwise aggressive measures" to "comfort care." ${ }^{54,55}$ Physicians who have a clear understanding of a DNR order will be able to reassure a patient that they will continue to receive desired care, but that if the patient dies, no attempt to resuscitate will be made.

Third, it is important to remind patients who choose full resuscitation status that additional decisions will need to be made if resuscitation is successful. Most patients who survive cardiopulmonary arrest end up worse off clinically and spend time in an ICU with life-support measures in place, such as mechanical ventilation and vasopressors. Even if they survive, there will likely be a period during which they are unable to speak for themselves. This situation puts the burden of decision making on their surrogates or an appointed durable power of attorney for health care (DPOA-HC). It is important to ask patients ahead of time whether there are conditions under which they would not want ongoing life-sustaining measures. For example, a person might opt for discontinuation of lifesupport measures if the physician and family agreed that there was only a minimal chance of cognitive recovery existed and that ongoing support was only prolonging inevitable death. To clarify the patient's wishes in this situation, you might ask, "Are there conditions that would be worse than death?" Encouraging the patient to share his/her wishes in this situation with a surrogate or DPOAHC will help to ensure those wishes are respected.

\section{Communication Techniques}

When discussing advance directives, it is important to give patients the chance to describe their life goals and their values to establish a context for understanding the role of life-sustaining treatments. One useful method to elicit these goals and values is to ask open-ended questions, followed by periods of silence so the patient has time to express himself/herself. In the second scenario, above, the physician used open-ended questions in several instances: "Tell me what you understand about your illness" and "As you look ahead, what worries you most?" Tulsky and colleagues documented that medical residents spoke $76 \%$ of the time in discussions with patients about code status. ${ }^{30}$ In an ideal case, this ratio should be reversed or at least be even, allowing patients the time to explain their thoughts. Acknowledging patients' emotions by stating simply, "You seem [angry/sad/perplexed]," and waiting for an answer can help patients feel they are being understood. Making empathic statements is another powerful communication technique that conveys understanding. ${ }^{56}$ Examples include, "That must be really sad for you," and "It must be frightening to be in so much pain." As noted, silence can also be a powerful tool. Clinicians tend to be uncomfortable with silence and so fill the gaps with words. Allowing for silence enables patients to digest what they have heard, encourages them to continue speaking, and shows them the clinician wants to hear what they have to say. When giving information about any medical issues and especially about CPR, it is important to explain concepts in lay terms and to avoid medical jargon. ${ }^{57}$ Additionally, nonverbal communication techniques such as making eye contact, head nodding, and leaning in toward the patient all help in communicating engagement in the conversation. Having the conversation in a quiet and private place and sitting at the same level as the patient or family is also important. It is always a good idea to check in with patients to assess their understanding. Simply asking, "Do you have any questions about what I said?" or "Does that all make sense?" gives patients the opportunity to ask for clarification. Attempting to summarize what a patient has said can also help to clarify misunderstandings. Useful phrases include, "Let me see if I've gotten this right..." or "I want to make sure that I understood what you're telling me...," followed by the clinician's synopsis of important points dis- 
TABLE 2

Useful Communication Techniques

- Ask open-ended questions followed by periods of silence
"Tell me what you understand about your illness."
"As you look ahead, what worries you most?"
- Acknowledge emotion
"You seem [angry/sad/perplexed]."
- Make empathetic statements
"That must be really hard for you."
"It must be terrible to be in so much pain."
- Use nonverbal communication techniques such as eye contact, head nodding,
leaning in toward the patient, sitting down, and sitting at patient's level
- Allow for silence
- Assess patient's understanding
"Do you have any questions about what I said?"
"Does that all make sense?"
- Confirm your own understanding
"Let me see if I've gotten this right."
"I want to make sure I understand what you've been telling me."
- Avoid medical jargon
- Use the "I wish" statement
"I wish there were more chemotherapy we could give you that would make a
difference."
- Use the "Hope for the best, prepare for the worst" statement
"I think we should hope that the chemotherapy works but prepare for the
possibility that it might not."

cussed. ${ }^{58}$ A summary of important communication techniques can be found in Table 2 .

There are 2 additional statements that can be very useful when patients and families are struggling with the reality of severe illness and are still hoping for longer life and cure. The first is the "I wish" statement, in which the clinician allies himself or herself with the patient's or family's wishes by stating, "I wish it were different. I wish there were more chemotherapy we could give you that would make a difference." ${ }^{59}$ Occasionally, when tension is developing because the clinician does not believe an intervention is warranted but the patient desires it nonetheless, the "I wish" statement can be a powerful way of realigning with the patient. For example, responding to a patient who says, "I want chemo to cure my cancer," with the statement "There is no chemotherapy to help you" can seem antagonistic. In contrast, saying, "I wish there were a treatment that would make your cancer go away" aligns the clinician with the patient and supports the patient. Another advantage of "I wish" statements is that they are true-the clinician does wish that there was an effective treatment and would gladly provide it if available. In general, "I wish" statements are more effective than "I'm sorry" statements, because the latter can be inter- preted as the clinician taking responsibility for the situation. When a provider says, "I'm sorry to give you this bad news," the patient may feel the need to say, "That's OK." On the other hand, saying, "I'm so sorry that your mother is dying," is very human and unlikely to be interpreted as the clinician taking responsibility for the death.

A similar technique is to use the statement "Hope for the best, prepare for the worst" when speaking with patients and families. ${ }^{60}$ For example, a physician could say, "I really wish your mother could get better, and we should still hope for that; at the same time, we need to prepare for what will happen if she doesn't get better." Once again, this phrase both allows the patient or family to continue hoping things will improve and the clinician to support this hope, while simultaneously beginning the process of planning for the more likely outcome. Over time, the patient and family often move toward accepting that the patient is dying. Finally, trying to help the patient or family maintain hope in the face of illness and death is challenging but important: "If your mother can't get better, are there other things you can hope for?" Helping to identify tangible and realistic goals, such as being free from pain, seeing an important family member one last time, or getting home can provide hope at a difficult time.

\section{Giving a Recommendation}

Most patients with serious illness and their families want help making complex and ethically charged decisions. When clinicians ask patients to make decisions unilaterally, patients often feel anxious, sometimes for weeks. ${ }^{61}$ Families are often paralyzed when faced with the very difficult decision of whether to withdraw life-sustaining interventions from a family member with an advanced terminal illness. Even if they understand on an intellectual level that ceasing to provide potentially curative or life-prolonging therapies is the best choice, they are not yet able to accept this decision on an emotional level and ultimately may feel responsible and then guilty for the patient's death. Physicians need to carry some of the burden of making these difficult decisions. One way to relieve family members of some of this guilt is to recommend a plan of care based on substituted judgment, that is, on what the patient said she or he wanted or what the family thinks the patient would have wanted. ${ }^{62-64}$ In addition, clinicians should use their medical expertise, experience, and understanding of the situation 
to make recommendations. The patient or family can then accept or reject the physician's advice, which maintains patient autonomy, yet not have to explicitly instruct the clinician to withdraw or limit life-sustaining interventions.

The preceding discussion and recommendations can guide scenarios like those presented at the beginning of this article. In the second conversation, the clinician had just told the patient that he could help her to achieve her goal of pain control and of returning and staying home.

Dr. S says, "I want to make sure I've understood what you've said. To summarize, you've told me how important it is to you to have your pain controlled, to have some good time with your husband and family at home, and not to come back to the hospital. Is that right?"

Mrs. G: "Yes, that's right."

Dr. S: "And how is your pain today?"

Mrs. G: "So much better. I'm hoping I can go home soon."

Dr. S: "That should be possible. In the next day or so, we will be getting you back onto medications that you can take by mouth. But before you go home, we need to figure out how we can support you and your family at home: get you ongoing help with pain control and any other issues that come up and support for your husband and family as well."

Mrs. G: "Yes, my family really needs support."

Dr. S: "Have you had any experience with hospice before? I'm thinking that that would be the best way to get you the support you and your family need."

Mrs. G: "Yes. When my sister died, she had home hospice. They were very good and helpful, especially to her husband, my brother-in-law. Yes, I would like that, as I just don't want to come back to the hospital. Hopefully, they can help my husband adjust to things."

Dr. S continues: "I think they will help your husband a lot, both before and also after your death." He pauses.

Mrs. G: "That's good. I worry about him so much."

Dr. S: "As you know, one of the important goals of hospice care is to keep you at home so you don't have to return to the hospital. And when the time comes, to help you die peacefully at home." Mrs. G nods. "What this also means is that they would not use CPR, that is, not do chest compressions, when you were actively dying."

Mrs. G: "Yes, I want to be able to go home and be at peace. The last thing I would want is someone thumping on my chest as I was dying." She smiles. tions?"

Dr. S.: "Do you have any other thoughts or ques-

Mrs. G: “Well, yes. I'm wondering if we can set up a time to talk with my husband about all of this. I think it would be helpful for him to talk with you. Would that be possible?"

Dr. S: "I would be happy to talk with your husband. When is he coming in?"

They negotiate a time.

Mrs. G: "I want to thank you for taking the time to talk with me. I am really grateful."

\section{CONCLUSIONS}

The decision about cardiopulmonary resuscitation is part of a larger conversation with a patient about how she or he wants to spend the rest of his/her life. Importantly, the decision should be made in context, rather than in isolation. Given the understanding that develops between physician and patient in the conversation above, it is not necessary to describe all the specific treatments that occur during CPR because the physician has already established that the patient does not want to return to the hospital, and she understands that she has a terminal condition and is dying. Through exploring a patient's goals and values, a clinician can discover a patient's preferences for care generally and come up with a comprehensive plan that addresses the particular individual's medical, social, and emotional needs. For physicians, few interventions are as important or rewarding as relieving patients' suffering and helping them attain their goals during and at the end of life.

Address for correspondence and reprint requests: Eva H. Chittenden, MD, Department of Medicine, University of California, San Francisco, 505 Parnassus Ave., Box 0131, San Francisco, CA 94143; Fax: (415) 514-2094; E-mail: evac@medicine.ucsf.edu.

Received 18 March 2006; revision received 25 May 2006; accepted 31 May 2006

\section{REFERENCES}

1. Tulsky JA, Fischer GS, Rose MR, Arnold RM. Opening the black box: how do physicians communicate about advance directives? Ann Intern Med. 1998;129:441-449.

2. Wenger N, Phillips R, Teno J, et al. Physician understanding of patient resuscitation preferences: insights and clinical implications. J Am Geriatr Soc. 2000;48:S44-S51.

3. Fischer GS, Tulsky JA, Rose MR, Siminoff LA, Arnold RM. Patient knowledge and physician predictions of treatment preferences after discussion of advance directives. J Gen Intern Med. 1998;13:447-454.

4. Pfeifer MP, Mitchell CK, Chamberlain L. The value of disease severity in predicting patient readiness to address end-oflife issues. Arch Intern Med. 2003;163:609-612.

5. A controlled trial to improve care for seriously ill hospitalized patients. The study to understand prognoses and preferences for outcomes and risks of treatments (SUPPORT). The SUPPORT Principal Investigators. JAMA. 1995;274:15911598. 
6. Reilly BM, Magnussen CR, Ross J, Ash J, Papa L, Wagner M. Can we talk? Inpatient discussions about advance directives in a community hospital. Attending physicians' attitudes, their inpatients' wishes and reported evidence. Arch Intern Med. 1994;154:2299-2308.

7. Emanuel LL, Barry ML, Stoeckle JD, Ettelson LM, Emanuel EJ. Advance directives for medical care-a case for greater use. N Engl J Med. 1991;324:889-895.

8. Lo B, McLeod G, Saika G. Patient attitudes to discussing life-sustaining treatment. Arch Intern Med. 1986;146:16131615.

9. Lamont EB, Siegler M. Paradoxes in cancer patients' advance care planning. J Palliat Med. 2000;3(1):27-35.

10. Meier DE, Back AL, Morrison RS. The inner life of physicians and care of the seriously ill. JAMA. 2001;286:3007-3014.

11. Johnston C, Pfeifer MP, McNutt R. The discussion about advance directives; patient and physician opinions regarding when and how it should be conducted. Arch Intern Med. 1995;155:1025-1030.

12. Block SD. Psychological considerations, growth, and transcendence at the end of life: the art of the possible. JAMA. 2001;285:2898-2905.

13. Pantilat S. Care of dying patients: beyond symptom management. West J Med. 1999;171(4):253-256.

14. Clayton J, Butow P, Arnold R, Tattersall M. Fostering coping and nurturing hope when discussing the future with terminally ill cancer patients and their caregivers. Cancer. 2005; 103:1965-1975.

15. Wissow LS, Belote A, Kramer W, Compton-Phillips A, Kritzler R, Weiner JP. Promoting advance directives among elderly primary care patients. J Gen Intern Med. 2004;19:944951.

16. Markson L, Fanale J, Steel K, Kern D, Annas G. Implementing advance directives in the primary care setting. Arch Intern Med. 1994;154:2321-2327.

17. Hare J, Nelson C. Will outpatients complete living wills? A comparison of two interventions. J Gen Intern Med. 1991;6: 41-46.

18. Meier DE, Gold G, Mertz K, et al. Enhancement of proxy appointments for older persons: physician counselling in ambulatory settings. J Am Geriatr Soc. 1996;44(1):37-43.

19. Sulmasy DP, Song KY, Marx ES, Mitchell JM. Strategies to promote the use of advance directives in a residency outpatient practice. J Gen Intern Med. 1996;11:657-663.

20. Reilly BM, Wagner M, Magnussen CR, Ross J, Papa L, Ash J. Promoting inpatient directives about life-sustaining treatments in a community hospital. Results of a 3-year timeseries intervention trial. Arch Intern Med. 1995;155:23172323.

21. Holloran SD, Starkey GW, Burke PA, Steele GJ, Forse RA. An educational intervention in the surgical ICU to improve ethical decisions. Surgery. 1995;118(2):294-299.

22. Sullivan AM, Lakoma MD, Block SD. The status of medical education in end-of-life care. A national report. J Gen Intern Med. 2003;18:685-695.

23. Weissman DE, Block SD. ACGME Requirements for end-oflife training in selected residency and fellowship programs: a status report. Acad Med. 2002;77(4):299-304.

24. Mullan PB, Weissman DE, Ambuel B, von Gunten C. Endof-life care education in internal medicine residency programs: an interinstitutional study. J Palliat Med. 2002;5:487496.
25. Sullivan AM, Warren AG, Lakoma MD, Liaw KR, Hwang D, Block SD. End-of-life care in the curriculum: a national study of medical education deans. Acad Med. 2004;79:760768.

26. Ury WA, Berkman CS, Weber CM, Pignotti MG, Leipzig RM. Assessing medical students' training in end-of-life communication: a survey of interns at one urban teaching hospital. Acad Med. 2003;78:530-537.

27. Plauth W, Pantilat S, Wachter R, Fenton C. Hospitalists' perceptions of their residency training needs: results of a national survey Am J Med. 2001;111(3):247-254.

28. Meisel A, Kuczewski M. Legal and ethical myths about informed consent. Arch Intern Med. 1996;156:2521-2526.

29. Morrison RS, Morrison EW, Glickman DF. Physician reluctance to discuss advance directives: an empiric investigation of potential barriers. Arch Intern Med. 1994;154:2311-2318.

30. Tulsky J, Chesney M, Lo B. How do medical residents discuss resuscitation with patients? J Gen Intern Med. 1995;10: 436-442.

31. Christakis NA, Lamont EB, Smith JL, Parkes CM. Extent and determinants of error in doctors' prognoses in terminally ill patients: prospective cohort study. Br Med J. 2000;320:469473.

32. Christakis N. Death Foretold; Prophecy and Prognosis in Medical Care. Chicago: University of Chicago Press, 1999.

33. Christakis N, Iwashyna T. Attitude and self-reported practice regarding prognostication in a national sample of internists. Arch Intern Med. 1998;158:2389-2395.

34. Janisch L, Mick R, Schilsky RL, et al. Prognostic factors for survival in patients treated in phase I clinical trials. Cancer. 1994;74:1965-1973.

35. Maltoni M, Pirovani M, Scarpi E, et al. Prediction of survival of patients terminally ill with cancer. Results of an Italian prospective multicentric study Cancer. 1995;75:2613-2622.

36. Yates JW, Chalmer B, McKegney FP. Evaluation of patients with advanced cancer using Karnovsky performance status. Cancer. 1980;45:2220-2224.

37. Mor V, Laliberte L, Morris JN, Wiemann M. The Karnofsky Performance Status Scale. An exam of its reliability and validity in a research setting. Cancer. 1984;53:2002-2007.

38. Lamont EB. A demographic and prognostic approach to defining the end of life. J Palliat Med. 2005;8(suppl 1):s12s21.

39. den Daas N. Estimating length of survival in end-stage cancer: a review of the literature. J Pain Symptom Manage. 1995; 10:548-555.

40. Lassauniere JM, Vinant P. Prognostic factors, survival, and advanced cancer. J Palliat Care. 1992;1992(8):4.

41. Pirovano M, Maltoni M, Nanni O. A new palliative prognostic score: a first step for the staging of terminally ill cancer patients. J Pain Symp Management 1999;17(4):231-239.

42. Vigano A, Dorgan M, Buckingham J. Survival prediction in terminal cancer patients: A systematic review of the medical literature. Palliat Med. 2000;14:363-374.

43. Reuben DB, Mor V, Hiris J. Clinical symptoms and length of survival in patients with terminal cancer. Arch Intern Med. 1988;148:1586-1591.

44. Maltoni M, Nanni O, Pirovano M. Successful validation of the palliative prognostic score in terminally ill cancer patients. J Pain Symptom Manage. 1999;17:240-247. 
45. Glare P, Eychmueller S, Virik K. The use of the palliative prognostic score in patients with diagnoses other than cancer. J Pain Symptom Manage. 2003;26:883-885.

46. Glare PA, Eychmueller S, McMahon P. Diagnostic accuracy of the palliative prognostic score in hospitalized patients with advanced cancer. J Clin Oncol. 2004;22:4823-4828.

47. Ebell MH, Becker LA, Barry HC, Hagen M. Survival after in-hospital cardiopulmonary resuscitation: a meta-analysis. J Gen Intern Med, 1998;13(12):805-16.

48. Moss A. Informing the patient about cardiopulmonary resuscitation: when the risks outweigh the benefits. J Gen Intern Med. 1989;4:349-355.

49. Faber-Langendoen K. Resuscitation of patients with metastatic cancer: Is transient benefit still futile? Arch Intern Med. 1991;151:235-239.

50. Diem SJ, Lantos JD, Tulsky JA. Cardiopulmonary resuscitation on television-miracles and misinformation. N Engl J Med. 1996;334:1578-1582.

51. Murphy DJ, Burrows D, Santilli S, et al. The influence of the probability of survival on patients' preferences regarding cardiopulmonary resuscitation. N Engl J Med. 1994;330:545549.

52. Schonwetter R, Walker R, Kramer D, Robinson B. Resuscitation decision making in the elderly: the value of outcome data. J Gen Intern Med. 1993;8:295-300.

53. von Gunten CF. Discussing do-not-resuscitate status. J Clin Oncol. 2001;19:1576-1581.

54. Lipton HL. Do-not-resuscitate decisions in a community hospital. Incidence, implications, and outcomes. JAMA. 1986;256:1164-1169.

55. Tolle SW, Tilden VP, Nelson CA, Dunn PM. A prospective study of the efficacy of the physician order form for lifesustaining treatment. J Am Geriatr Soc. 1998;46:1170-1171.

56. Lo B, Quill T, Tulsky J, for the ACPAE-o-LCCP. Discussing palliative care with patients. Ann Intern Med. 1999;130:744749 .

57. Back AL, Arnold RM, Baile WF, Tulsky JA, Fryer-Edwards K. Approaching difficult communication tasks in oncology. $C A$ Cancer J Clin. 2005;55(3):164-177.

58. Coulehan JL, Platt FW, Egener B, et al. "Let me see if I have this right...": words that help build empathy. Ann Intern Med. 2001;135(3):221-227.

59. Quill TE, Arnold RM, Platt F. "I wish things were different": expressing wishes in response to loss, futility, and unrealistic hopes. Ann Intern Med. 2001;135:551-555.

60. Back AL, Arnold RM, Quill TE. Hope for the best, and prepare for the worst. Ann Intern Med. 2003;138:439-443.

61. Gattellari M, Voigt KJ, Butow PN, Tattersall MHN. When the treatment goal is not cure: are cancer patients equipped to make informed decisions? J Clin Oncol. 2002;20:503-513.

62. Winzelberg GS, Hanson LC, Tulsky JA. Beyond autonomy: Diversifying end-of-life decision-making approaches to serve patients and families. J Am Geriatr Soc. 2005;53:10461050.

63. Ende J, Kazis 1, Ash A, Moskowitz M. Measuring patients' desire for autonomy: decision making and informationseeking preferences among medical patients. J Gen Intern Med. 1989;4(1):23-30.

64. Quill TE, Brody H. Physician recommendations and patient autonomy: finding a balance between physician power and patient choice. Ann Intern Med. 1996;125:763-769. 